\title{
Using Instructional Software to Improve Oral Performance of Taiwanese Speakers of English in Higher Education
}

\author{
Yen-Tzu Chen ${ }^{1}$, Hsiao-Wen Huang ${ }^{2} \&$ Che-Hung Liu ${ }^{1}$ \\ ${ }^{1}$ Assistant Professor, Department of Business and Management, National University of Tainan, Taiwan \\ ${ }^{2}$ Assistant Professor, Department of Information Management, Chang Jung Christian University, Taiwan \\ Correspondence: Hsiao-Wen Huang, Department of Information Management, Chang Jung Christian University, No. \\ 1 Changda Rd., Gueiren District, 71101, Taiwan. Tel: 886-6-2785123. E-mail: victoria@mail.cjcu.edu.tw
}

Received: October 20, 2013 Accepted: November 2, 2013 Online Published: November 8, 2013

doi:10.5430/ijelt.v1n1p42 URL: http://dx.doi.org/10.5430/ijelt.v1n1p42

\begin{abstract}
The global society perceives English as an important skill; most people expend significant efforts and resources to learn English. However, as in the other Asian countries, Taiwanese education focuses exclusively on traditional teaching in language courses, overlooking interactions and cultural concepts. Thus, students' ability to communicate orally in English remains relatively low. Existing literature indicates that Computer-Assisted Language Learning (CALL) can enrich language learning as computers provide many functions to enhance lectures in a meaningful and effective manner. In particular, CALL can incorporate speech recognition software to help develop oral language and practice pronunciation. Integrating CALL technology into traditional language courses may improve Taiwanese students' oral performance. The current study utilized learner-centered design and second language acquisition theories as guidelines to identify relevant software; the SECTIONS model and evaluation criteria were used to select the most suitable program for integration into a traditional course. The experimental design was administered to two sophomore English classes whose students were not majoring in English at a private university in Taiwan over an eight-week period. Pre- and posttests were used to identify language achievement during the study. Changes in the Spoken English Test (SET) resulting from the treatment were found to have no statistically significant difference, but the experimental group demonstrated greater improvement on the sentence mastery section and vocabulary. The research results shed some light to reinforce the literature exploring the application of computer software in language education, and also provide language learners implications and recommendations.
\end{abstract}

Keywords: computer-assisted language learning (CALL), learner-centered design (LCD), second language acquisition (SLA), software selection

\section{Introduction}

The global society perceives English as an important skill; most people expend significant efforts and resources to learn English. However, as in the other Asian countries, Taiwanese students' English oral proficiency is in urgent need of improvement as learners have little or no opportunity to speak the language they are learning outside the classroom, while classroom learning often lacks authentic cultural aspects and interactions. According to Yang and Chen (2007), one reason that Taiwanese students cannot improve their English ability is the lack of interactive English learning environments in school. Teachers often focus on teaching learners to pass exams, not how to speak English well. For example, students learn vast amounts of vocabulary without understanding the nuances of when to use a particular word or phrase. Students focus almost exclusively on memorizing grammar rules and vocabulary meanings. Moreover, in Taiwanese classrooms authentic materials such as cultural concepts are particularly scarce (Yang \& Chen, 2007). Interactions promoting collaborative learning activities are often missing from the learning process. Meanwhile, interaction among peers is limited as the traditional norm is for the teacher to lecture while students are passive participants. Moreover, learners have limited opportunities to speak the second language learned outside of class (Jepson, 2005). Thus, the problem identified for study was the poor quality of spoken English as a result of limited or no opportunities to speak English as a two-way communication.

When the learning environment is ineffective or fails to meet students' needs, incorporating instructional technology such as computer-assisted language learning (CALL), into the classroom experience may improve the process (Lai, 2006). CALL technologies can be connected to the Internet, providing not only integrated environments that include 
graphics, videos, sounds, speech recognition technology, and CD-ROM capabilities, but also additional opportunities to interact with authentic situations and communicate with native speakers and experts. As such, CALL was used to provide a solution for improving Taiwanese students' oral performance, thereby warranting study.

\section{Background Literature}

\subsection{Technology Integration}

Computer technology is a powerful vehicle that can be integrated into second language acquisition (SLA) to improve teachers' abilities to enhance and empower students' learning. Technology integration aims to create a match between technology options and application contexts through the investigation of evaluation and refinement activities (Iansiti, 1997); In other words, such integration is like a bridge connecting a meaningful match between technology and learning context in education. Technology integration enables educators to make learning more active, provides real-world information through a living medium (i.e., the Internet), and helps solve real-life problems (Lai, 2006; Wang, 2005). Technology can open new doors for teachers limited by available resources. It exposes learners to authentic language use and speakers and serves to engage learners (and keep them engaged) in learning. As technological advances lead to improved designs in language software and courseware, enabling learners to acquire a second language more efficiently, teachers are challenged to keep up with the ever-changing technology.

When educators integrate technology into their courses, they must identify suitable software and deal with learners at differing levels. According to Wang (2005), different learners have different needs; however, these needs are measured using the same methods. Moreover, instructors have to determine how to pay the same amount of attention to each learner while addressing learners' varying needs in technology (Jepson, 2005). For example, if one learner's listening skills are not as advanced as his or her classmates' skills, the language teacher may choose a slower song to play during class; however, more advanced classmates may not be amenable to such accommodations. Thus, the lower-level learner may need additional assistance outside the classroom.

Teachers need to be aware of students' needs and integrate technologies effectively and appropriately in order to enhance learning opportunities for students. For example, lower-level learners tend not to use CD-ROMs effectively, often choosing to focus only on audio and textual options. Meanwhile, higher-level learners may prefer audio practice (Hegelheimer \& Tower, 2004). If teachers attempt to integrate technology, they should monitor students' responses carefully to ensure the material used is targeting the specific concept for which it is intended. In addition, teachers have to consider how learners adapt to such environments and their experience and ability to use the technology because learners' technological abilities affect their performances in learning a second language in a technology environment (Ware, 2004).

\subsection{Computer-Assisted Language Learning (CALL)}

According to Delcloque (2000), CALL uses computer technology as an aid in the presentation, reinforcement, and assessment of material to be learned; in addition, CALL usually involves a substantial interactive element. Many technology environments for second language learning rely on CALL, using different programs to enrich students' experiences and assist their learning (Hampel, 2006). CALL helps learners learn a language by producing highly interactive learning environments, thereby providing effective support for language teaching and learning (Laghos \& Zaphiris, 2005). In particular, Lai (2006) mentioned that CALL technologies can provide learners with independent and collaborative learning environments; learners can reduce stress and enhance their self-instruction and self-confidence through games and communicative activities. Applying artificial intelligence methods and learning technology engines in the CALL environment can also enhance students' abilities to gain more meaningful education in the learning environment (Karlstrom, Pargman, \& Ramberg, 2005). Thus, CALL technologies can enhance the learning environment in various meaningful ways for learners.

Laghos et al. (2005) determined that improvements in technology have allowed graphics, videos, sounds, and new delivery media to be integrated into CALL systems to connect people around the world through primarily multimedia, web-based, and online systems. Multimedia and web-based CALL systems are usually delivered on $\mathrm{CD}-\mathrm{ROM}$ and run offline, whereas online CALL is another form of e-learning. The authors concluded that three factors will affect the present as well as immediate future of CALL: computer-assisted language testing, such as the TOEFL; course-management systems (CMS) packages like WebCT and Blackboard; and intelligent CALL-also called ICALL - which applies to artificial-intelligence methods and technologies for language learning.

One way to incorporate CALL technologies is through the use of specific applications available on CD-ROMs. By integrating a set of learning materials on CD-ROMs through CMS packages, CALL technologies become 
increasingly interactive and flexible, making them more effective in language courses. Through the utilization of games and communication-based activities on CD-ROMs, learners instruct themselves more effectively, reduce their anxiety, and become more self-assured. At the same time, students' learning processes can be analyzed and recorded as data, enabling teachers to support learners' specific needs in a meaningful way (Lai, 2006). Meanwhile, learners have access to information about the target language from the CD-ROMs and can use the CMS tools to communicate or discuss issues with both teachers and peers.

However, language teachers must be careful in choosing and integrating CMS into the learning environment. Although many language schools and researchers are trying to apply CMS in language courses, CMS is not specifically designed for language teaching (Laghos et al, 2005). One activity teachers can incorporate is rapport-building through CALL. In this scenario, students practice mimicking native fluency. Jiang and Ramsay (2005) attempted to discover whether using rapport-building through CALL in learning second languages such as Chinese extended opportunities beyond the interactions of the traditional (face-to-face) classroom. They posted sound-file questions on the WebCT discussion board each week throughout the semester. Language learners recorded their answers to these questions in sound files as well. At the conclusion, both learners and teachers indicated that the process of communication through sound files was enjoyable as well as beneficial. Ware (2004) also mentioned that online discussion boards provide learners with more time to reflect on the target language and share ideas than face-to-face speech does. Students can more easily work in small groups using the text and image functions of CALL. Such activities can motivate learners and enhance their learning.

Zeiss and Isabelli-García (2005) further determined that the CALL environment helped learners understand the culture of the target language more deeply and encouraged them to pursue additional study, including study abroad. In addition, Ware (2004) reported that language students enjoyed communication practices using CALL because they did not have to be as concerned with their accent as they did in face-to-face conversations. Consequently, such communication can provide a protected place in which language students feel freer talk and practice the target language more comfortably. In other words, CALL learning environments can engage students in more authentic and motivated learning, ensuring that they get the most out of the activity and interaction while enhancing learning.

Although computer software applications can be beneficial in CALL environments for language courses, Redfield and Campbell (2005) pointed out that learners often feel isolated when using web-based software applications by themselves without instructor direction or involvement. As a result, learners' motivation may decrease, or they may limit their access to potential learning. Thus, in using such tools, teachers must consider learners' potential feelings of isolation and create more communication opportunities online or in traditional courses. Learners can discuss questions with peers or teachers while using computer software applications. For example, the instructor may set a time when everyone uses an online chat room or encourage students to share their ideas in classes to communicate with others to discuss questions encountered during the activity or after using the software.

In addition, Hampel (2006) determined that beginning learners with lower listening skills have more problems using CALL technologies effectively. When the instructor speaks the target language in an audio CALL setting, he or she should repeat the text more often and more slowly, finding a special way to explain the meaning to the learners or using their first language to continue the course to accommodate limited vocabulary and lower listening skills. Integrating CALL software into the field of second language can enrich traditional, face-to-face and online courses, but more consideration must be made in second language acquisition courses. In particular, when learning a second language in a CALL environment, learners may need additional contact with the instructors for both language skill and technology tool support.

Many education researchers and software designers have conducted studies into second language learning using CALL in order to measure learners' improvement in mastering second language skills; most research has found positive outcomes. For example, Jiang et al, (2005) reported that CALL sound-file responses and e-mail exchanges produced effective language learning, while Lo, Wang, and Yeh (2004) reported that EFL students effectively improved in displaying their confidence in answering questions by using a Web-based English preposition course. These studies suggest that the computer-assisted instruction program increased overall student learning. However, Chen, Belkada, and Okamoto (2004) reported communication for language learning in a CALL environment did not prove to be successful in helping learners restructure linguistic knowledge. These authors conducted an experimental study involving 20 university-level EFL Chinese students randomly assigned to either a control group in which language was used for a functional purpose or an experimental group in which language was used for a communicative purpose. The study sought to examine the effectiveness of the web-based course in different interactive forms in a CALL environment. The researchers determined that many language learners feel 
uncomfortable speaking the target language or worry about their accent; based on the scaffolding tools, the CALL environment should provide a recording of a native speaker saying every sentence so that learners can practice their pronunciation. The native speaker can start with simple sentences and advance gradually as learners become increasingly comfortable with basic sentences. In addition, software needs to provide a sound-matching tool to help students compare their speaking with native speakers. Additional chances to practice mean that learners have more opportunity to develop their confidence in communicating with others. Clearly teachers need to be aware of students needs and integrate CALL technologies effectively and appropriately in order to enhance learning opportunities for students.

The second language learning environment needs to consider language learners' unique needs, such as computerized dictionaries and vocabulary activities. Knutsson, Pargman, and Eklundh (2003) mentioned that language technology applied in second language writing may be a good tool for assisting learners, but two facts have to be considered: the existence of false alarms generated by the program and the limited recall of important linguistic constructions in learners' texts. Second language learners who get false alarms and spend too much time focusing on them will consequently access the wrong context and may adopt inappropriate concepts regarding language technology. Learners may feel pressured and frustrated when dealing with such situations.

Similarly, Knutsson et al. (2003) conducted two studies focusing on using the computer application Granska, a Swedish grammar checker developed by the Royal Institute of Technology as a tool to support the writing of learners who use Swedish as a foreign language. The studies found that learners still encounter some difficulties when using this program, but language tools can help learners focus on form. Meanwhile, Karlstrom et al. (2005) pointed out that recent second language learning theories have struck a balance between learning linguistic forms and communicating, which the authors refer to as "a focus on form." However, this balance of concentrating on communication using linguistic forms does not combine effectively with CALL systems. In addition, grammar and spelling checkers are intelligent tools, but still have two problems: fallibility (i.e., the lack of fail-proof technology) and formality (i.e., inflexible tools). Learners may lose their motivation to learn - especially when they must also deal with false alarms that could lead learners in the wrong direction.

Karlstrom et al. (2005) focused on the learning perspective of how language technology and computer networks can be combined in the context of use, student-system relationships, interaction and technology, and fallibility and formality. In the context of use, reducing rigid communicative aspects and "tools" is not based on artificial intelligence. In the student-system relationship, real language use should be provided when writing and editing documents; through collaboration and discussion with other humans, the learning technology engine relieves incorrect and inappropriate assumptions. During interactions, linguistic information is available in service modes at the student's request; students are not tutored by the language engine, but by making their own linguistic decisions. Thus, through technology, "formal" (e.g., learning technology) and "non-formal" (communication) technologies connect. As such, the learner's part of the learning technology engine should be improved upon and incorporated into other engines applying previous researchers' suggestions provided herein to the CALL environment will promote SLA.

Indeed, Heift and Toole (2002) argue that student models have been applied in CALL environments and are commonly accepted in language learning, resulting in positive outcomes in individualized language instruction in CALL applying SLA. The researchers used Intelligent Language Tutoring Systems (ILTS). Designed for second language learners, ILTS provides the correct answers and points out errors from the practice, incorporating interactive vocabulary and grammar exercises as well as recording learners' performance for future study. Heift and Toole focused on the different levels of learners in adaptive language learning based on the student model of the ESL tutor in three categories: novice, intermediate, and expert. The student model of the ESL tutor is based on the learner's performance; information on performance is used to formulate instructional feedback and assessment remediation while providing additional practice to address the learner's weaknesses. Using this application, learners can determine their language ability and start in different categories, utilizing interactive exercises that motivate learners. In addition, the inherent scaffolds vividly assist learners in practicing their weaknesses.

Meanwhile, Stepp-Greany (2002) surveyed beginning Spanish learners to determine their perceptions about Technology-Enhanced Language Learning (TELL). The participants were enrolled in courses that integrated computer-assisted instruction, including a CD-ROM with a mystery story, interactive activities such as visiting Spanish-speaking sites, threaded discussions involving posting opinions relative to the chapter theme, electronic pen pal communications about Hispanic cultures, online sources such as dictionaries, and an optional drill and tutorial program. These tools were provided to meet language learners' needs and, by incorporating a diversity of learning 
activities, to give learners a better SLA environment. A high number of students agreed or strongly agreed that the instructor played an important role in helping beginning language learners in TELL. Most learners agreed that they felt that satisfactory access to a computer and lab activities benefited their communicative skills. The results indicate that students gained confidence in their abilities thanks to the work using computers.

The studies detailed herein indicate that the CALL environment can provide diversified ways in which to lead language students to practice and master second languages while providing them with a truly safe place. Although many issues remain that need to be addressed in order improve the CALL environment, as long as educational software designers can meet learners' needs, the CALL setting can provide learners with a practical environment.

\subsection{Learner-Centered Design (LCD)}

When CALL software is widely used in second language acquisition, educators have to consider whether it truly incorporates scaffolds for learners. Learner-Centered Design (LCD) is an area of human-computer interaction research that focuses on learners' needs by designing software scaffolds to support novice learners in meaningful engagement in learning about the content and work practices of an unfamiliar domain (Luchini, Quintana, \& Soloway, 2004). According to Soloway, Guzdial, and Hay (1994), learners are the center of the design; thus, learners' special needs must be addressed - namely, understanding is the goal, motivation is the basis, diversity is the norm, and growth is the challenge. Scaffolding strategies for LCD software meet these special needs. Modeling, coaching, and critiquing can be effective strategies to help learners understand. To motivate learners, designers should focus on low overhead and immediate success. Moreover, as learners represent a diverse set of backgrounds and various interests, skills, and learning styles, educators can use collections of various techniques to solve the "one-size-fits-all" application problem. Finally, software needs to be adaptable in order to deal with learners' growth in unknown domains. Incorporating scaffolding strategies in LCD software helps ensure that the constructivist learning theory and social constructivism are considered in educational software (Becker, 2006).

The constructivist learner theory asserts that activities and social processes of meaning construct learning while the reflection of the acts of conversing with others and constructing artifacts builds understanding (Phillips \& Soltis, 2003). LCD promotes the learning-by-doing approach; completing a meaningful task is the most effective way to help novice learners manipulate the material they are learning (Quintana, Krajcik, \& Soloway, 2001). Meanwhile, the social constructivist learning theory extends the constructivist approach by situating social perspectives and interaction within cultural environments (Farmer \& Hughes, 2005). In order to develop an understanding of the common practices, tools, and values of a professional culture, learners need to participate in the professional work culture and build their knowledge (Quintana, Krajcik, \& Soloway, 2002). However, learners need to actively engage in authentic activities from the work domain using scaffolds to help them understand the new work activities (Quintana et al., 2002).

According to Vygotsky's zone of proximal development-an important tool for defining scaffolding in learning (Peregoy \& Boyle, 2004) - teaching is not focused on today; rather, it emphasizes tomorrow. Students need to be challenged, while receiving assistance and support, to develop to the next level. Such assistance and support are called scaffolding (Gánem Gutiérrez, 2006). Learner-centered applications focus on creating a software design that enables learners to learn, supporting them in accomplishing new tasks; such design generally includes scaffolding features to assist learners as they engage in activities beyond their normal abilities (Leonard, Davis, \& Sidler, 2005). For example, software may require a language learner to write a grammatically correct sentence using new vocabulary. According to Leonard et al. (2005), existing software's scaffolds focus on interactions with a particular learner.

Luchini, Quintana, and Soloway (2003) conducted a comparison study involving 33 eighth graders in two science classes at a private school to observe how handheld devices could support students when integrated into their regular inquiry-based science curriculum. They also explored how students used a handheld Packet PiCoMap (a learner-center concept mapping tool) and PiViT (a desktop concept mapping tool) over a nine-month period. A visually represented concept map incorporated each individual idea inside nodes, with a directional line pointing to the relationship between two ideas. The authors used an LCD concept - what learners need and how scaffolds can work for them - to design the handheld pocket PiCoMap. They used concept colors to help learners organize the map, incorporating link scaffolds to help learners understand the relationships between each idea. In addition, they integrated concept notes, link notes, map notes, and text maps to assist learners in articulating their understanding of concepts, relationships, and maps of the science activities. The results indicated that students tend to have more difficulty using and organizing such handheld tools due to the small screens; however, students completed the learning activities successfully and, through scaffolds, created better concept maps. Thus, this study extended the 
LCD principles, providing a good example of how to apply LCD in educational software.

Luchini et al. (2003) further demonstrated that scaffolds can play important roles in assisting students to learn using educational software while providing positive interactions between learners and the computer. When the user is also a learner, educational software designers should not only consider user-centered design principles, but also need to address learners' special needs (Soloway et al., 1996).

\subsection{Second Language Acquisition Theories}

When the LCD approach is used to meet learners' needs evident in the CALL environment, it should address each function and tool in the software in order to integrate scaffolds successfully. A truly helpful SLA environment also needs to be considered. Krashen's SLA theories - based on his five hypotheses, serve as the foundation of the second language learning field (Peregoy \& Boyle, 2004) and provide language teachers with the best leads for determining ideal environments for language learners. He labeled them acquisition-learning, monitor, natural order, input, and affective filter (Krashen, 1987, 1988).

In the acquisition-learning hypothesis, Krashen $(1987,1988)$ defined acquisition as a natural language process in which meaningful interactions with native speakers using the target language occur without focusing on form. Learners will pick up a language more easily in communicative learning rather than forcing them to learn through the use of grammatical rules. Krashen suggested teaching language by focusing on communication, not forcing learners to learn by rote rules (Warner, 2004). The CALL software environment can address this need through the use of audio only or video interactive capabilities, which can provide a platform for natural communications for SLA while conveying knowledge from the target knowledge to the learners to supplement their acquisition of the language. For example, the software provides a real situation, communicating with the learners according to their answers. A CALL-structured CD-ROM that incorporates rich, hypermedia materials can facilitate learning in terms of providing a central repository for information storage and a functionality to enable the information retrieval and use by learners.

Meanwhile, according to the monitor hypothesis, Krashen argued that learners watch their language outcomes from interactive or writing communication by applying their grammatical knowledge to plan, monitor, and correct their output. However, the monitoring function only works when learners have enough time to do it, focusing on form or correctness in light of the rule (Krashen, 1987, 1988). Indeed, the effective use of the monitoring function involves three requirements: (a) the second language learner has sufficient time at his/her disposal; (b) the learner focuses on form or thinks about correctness; and (c) the learner knows the rules. If these three requirements are met, the CALL setting can provide automated language editing functions to monitor students' exercises and provide suggested corrections. However, it should not be too automated or the purpose of learning will be missed and students can complete the activity without learning how to actually process and become involved in it (Luchini et al, 2003). For example, the scaffolds can highlight students' errors and provide suggestions so that students can try to correct them on their own. The software can identify students' pronunciation and tones using speech recognition technology. In addition, students can hear the voice of native speakers and compare it to their speech to identify their errors themselves.

Krashen's (1994) natural order hypothesis involves a calculable progression; language learners acquire - not learn-language rules, where the order of acquisition is affected by the non-native language learner's age, background, and conditions of exposure (Liaw, 2006). The natural order patterns of SLA exist in the second language development without following those of the first language acquisition patterns. The CALL environment can provide platforms for natural communications for SLA and a structure compatible to natural order for second language learning. As previously stated, lower-level learners tend to choose to focus on audio and textual options, while higher-level learners prefer audio practice (Hegelheimer \& Tower, 2004). As such, CALL scaffolds need to focus on other options, such as listening and speaking, to ensure that a structure that fits the behavioral patterns of the learner group is embedded in the CALL setting.

According to the Krashen's input hypothesis, SLA is the direct result of learners understanding the target language by acquiring it in natural communication situations in which the linguistic structures used are beyond learners' current level-in other words, $i+1$, where $i$ refers to input and +1 represents the challenging level (Peregoy et al, 2004). Krashen's input hypothesis was built on Vygotsky's zone of proximal development; both emphasize language acquisition through human social interaction-communication (Zha, Kelly, Park, \& Fitzgerald, 2006). The CALL environment can provide platforms for natural communications to facilitate SLA and, with the automatic selection of " $i+1$ " questions and exercises for second language learning, the scaffolds can assist learners by providing examples or ideas to provide immediate success or increase their motivation. 
Finally, according to Krashen's (1987) affective filter hypothesis, learners' social-emotional variables can affect SLA. When these variables occur in a low-anxiety learning environment and students have the motivation and self-confidence to learn, learning results are best. Thus, the best results of SLA occur when learners have high motivation, self-confidence, a good self-image, and a low level of anxiety while learning. The CALL setting enables individuals to work at individual paces while focusing on providing positive feedback to learners that meets needs addressed by the hypothesis and increases motivation.

Krashen's SLA theories inform educators in applying CALL to deliver language instruction. Thus, instructors and educational software designers should consider SLA's unique characteristics as well as a learning centered approach when designing and planning an instructional curriculum.

Most teachers integrating computer technology into the curriculum have tended to focus on non-oral activities, such as software or Web-based reading, listening, vocabulary, or gap-filling type activities, due to the challenges of accessing oral language development using technology (Barr et al., 2005). The most popular recent technology for helping develop oral language is speech recognition software. Hincks (2003) pointed out that speech recognition software is sensitive and accurate enough to enhance learners' oral language ability. Table 1 summarizes how Krashen's SLA theories and LCD can be used to evaluate language software that includes speech recognition technology.

Table 1. Using Krashen's SLA theories and LCD approach to evaluate language software that includes speech recognition technology

\begin{tabular}{|c|c|c|c|c|c|c|}
\hline \multirow[t]{2}{*}{ SLA Theories } & \multicolumn{6}{|c|}{ Language Software with Speech Recognition Technology } \\
\hline & $\begin{array}{l}\text { Live Interactive } \\
\text { English }\end{array}$ & Traci Talk & Tell Me More & $\begin{array}{l}\text { Microsoft } \\
\text { Encarta } \\
\text { Interactive } \\
\text { English } \\
\text { Learning }\end{array}$ & $\begin{array}{l}\text { MyET (My } \\
\text { English Tutor) }\end{array}$ & Rosetta Stone \\
\hline $\begin{array}{l}\text { Acquisition-Learning } \\
\text { \& LCD }\end{array}$ & $\begin{array}{l}\text { Role play and } \\
\text { watch video }\end{array}$ & Role play & $\begin{array}{l}\text { Interact with } \\
\text { computer by } \\
\text { choosing correct } \\
\text { answers; the } \\
\text { dialogue } \\
\text { develops } \\
\text { according to a } \\
\text { learner's } \\
\text { response }\end{array}$ & $\begin{array}{l}\text { Watch video } \\
\text { to learn about } \\
\text { daily use of } \\
\text { target } \\
\text { language. }\end{array}$ & $\begin{array}{l}\text { Read articles } \\
\text { relating to } \\
\text { learner's daily } \\
\text { life }\end{array}$ & $\begin{array}{l}\text { Use real-life } \\
\text { images to } \\
\text { connect to the } \\
\text { meaning of } \\
\text { new language }\end{array}$ \\
\hline $\begin{array}{l}\text { Monitor } \\
\& \text { LCD }\end{array}$ & $\begin{array}{l}\text { Record voice } \\
\text { and compare } \\
\text { with a native } \\
\text { speaker }\end{array}$ & $\begin{array}{l}\text { Listen } \\
\text { carefully, } \\
\text { speak clearly, } \\
\text { and ask } \\
\text { correct } \\
\text { questions in } \\
\text { conversations } \\
\text { to solve the } \\
\text { mystery }\end{array}$ & $\begin{array}{l}\text { Use spoken } \\
\text { error tracking } \\
\text { system in 3D } \\
\text { animations to } \\
\text { identify } \\
\text { differences } \\
\text { between native } \\
\text { speakers and } \\
\text { learners }\end{array}$ & $\begin{array}{l}\text { Pronouncing } \\
\text { sounds } \\
\text { incorrectly } \\
\text { causes the } \\
\text { software to } \\
\text { automatically } \\
\text { play the video } \\
\text { to help } \\
\text { learners } \\
\text { practice } \\
\end{array}$ & $\begin{array}{l}\text { The automatic } \\
\text { speech analysis } \\
\text { system } \\
\text { analyzes the } \\
\text { pronunciation, } \\
\text { pitch, timing, } \\
\text { and emphasis, } \\
\text { pointing out } \\
\text { problems to } \\
\text { learners }\end{array}$ & $\begin{array}{l}\text { Speech } \\
\text { recognition } \\
\text { technology } \\
\text { compares } \\
\text { differences } \\
\text { between voices } \\
\text { of native } \\
\text { speaker and } \\
\text { learners. }\end{array}$ \\
\hline $\begin{array}{l}\text { Natural Order } \\
\& \text { LCD }\end{array}$ & $\begin{array}{l}\text { Learners } \\
\text { control the } \\
\text { teacher's } \\
\text { speed; different } \\
\text { functions (e.g., } \\
\text { dictionary) }\end{array}$ & $\begin{array}{l}\text { A series of } \\
\text { task-based } \\
\text { conversation } \\
\text { with } \\
\text { characters }\end{array}$ & $\begin{array}{l}\text { Video scenes } \\
\text { include } \\
\text { interactive } \\
\text { dialogues, } \\
\text { pronunciation } \\
\text { practice, } \\
\text { comprehension } \\
\text { activity, etc. }\end{array}$ & $\begin{array}{l}\text { Units } \\
\text { contain } \\
\text { listening and } \\
\text { speaking } \\
\text { practice; } \\
\text { learning } \\
\text { activities } \\
\text { offer } \\
\text { different } \\
\text { exercises by } \\
\text { learner's } \\
\text { choices }\end{array}$ & $\begin{array}{l}\text { Learners can } \\
\text { choose } \\
\text { different } \\
\text { native models }\end{array}$ & $\begin{array}{l}\text { Uses } \\
\text { learner's first } \\
\text { language to } \\
\text { provide clues } \\
\text { from new } \\
\text { images }\end{array}$ \\
\hline
\end{tabular}




\begin{tabular}{|c|c|c|c|c|c|c|}
\hline $\begin{array}{l}\text { Input } \\
\& \text { LCD }\end{array}$ & $\begin{array}{l}\text { Practice } \\
\text { exercises }\end{array}$ & $\begin{array}{l}\text { Solve } \\
\text { challenges } \\
\text { to proceed } \\
\text { to the next } \\
\text { level }\end{array}$ & $\begin{array}{l}\text { Receive a } \\
\text { score when } \\
\text { imitating a } \\
\text { phase or } \\
\text { sentence } \\
\text { recorded by a } \\
\text { native speaker }\end{array}$ & $\begin{array}{l}\text { After } \\
\text { finishing a } \\
\text { unit, learners } \\
\text { complete a } \\
\text { virtual } \\
\text { challenge. }\end{array}$ & $\begin{array}{l}\text { Get clear } \\
\text { feedback and } \\
\text { scores to } \\
\text { understand } \\
\text { their current } \\
\text { speaking } \\
\text { level and } \\
\text { improvement. }\end{array}$ & $\begin{array}{l}\text { Start with } \\
\text { basics (e.g., } \\
\text { vocabulary } \\
\text { for saying a } \\
\text { sentence) }\end{array}$ \\
\hline $\begin{array}{l}\text { Affective Filter } \\
\& \text { LCD }\end{array}$ & $\begin{array}{l}\text { Choose topics } \\
\text { of interest or } \\
\text { media (e.g., } \\
\text { games, popular } \\
\text { songs MV, 3D } \\
\text { animations). }\end{array}$ & $\begin{array}{l}\text { Virtually } \\
\text { hands-free } \\
\text { interaction } \\
\text { motivates } \\
\text { learners to } \\
\text { play }\end{array}$ & $\begin{array}{l}\text { Dialogue } \\
\text { develops } \\
\text { according to } \\
\text { the responses } \\
\text { learners } \\
\text { choose }\end{array}$ & $\begin{array}{l}\text { Choose to } \\
\text { interact with } \\
\text { different } \\
\text { roles in } \\
\text { real-time 3D } \\
\text { animated } \\
\text { environment. }\end{array}$ & $\begin{array}{l}\text { Various } \\
\text { virtual } \\
\text { learning } \\
\text { communities; } \\
\text { learners can } \\
\text { discuss with } \\
\text { other } \\
\text { learners. }\end{array}$ & $\begin{array}{l}\text { Engage in } \\
\text { interactive, } \\
\text { life-like } \\
\text { conversations } \\
\text { based on } \\
\text { context. }\end{array}$ \\
\hline
\end{tabular}

\subsection{Software Selection}

As educational technology continues to evolve and improve, computer-based instruction has become a useful learning tool that can be conducive to student learning (Hughes, 2005). Many computer and web-based software applications have been developed to help students learn. To address students' needs and provide relevant educational tools, teachers must be proficient and critical users of technology, carefully choosing software programs (Lacina, 2004). Teachers have to consider the learners' needs in conjunction with the teaching and learning approaches while avoiding ineffective software in the field as, when ineffective software is used, poor learning can result.

Software selection - which has become a major issue for teachers - is "a process undertaken outside the classroom by a teacher or group of teachers who are well informed about the education issues of computing" (Blease, 1986, p. 4). Bates and Poole (2003, pp. 79-80) proposed a SECTIONS model for software selection from the teacher's perspective:

"S Student: what is known about the students — or potential students - and the appropriateness of the technology for this particular group or range of students?

E Ease of use and reliability: how easy is it for both teachers and students to use? How reliable and well tested is the technology?

C Cost: what is the cost structure of each technology? What is the unit cost per learner?

$\mathrm{T}$ Teaching and learning: what kinds of learning are needed? What instructional approaches will best meet these needs? What are the best technologies for supporting this teaching and learning?

I Interactivity: what kind of interaction does this technology enable?

O Organizational issues: What are the organizational requirements and the barriers to be removed before this technology can be used successfully? What changes in organization need to be made?

$\mathrm{N}$ Novelty: how new is this technology?

S Speed: how quickly can courses be mounted with this technology? How quickly can materials be changed?"

The SECTIONS model is an amended form of the ACTIONS model (i.e., access, cost, teaching and learning, interactivity and user-friendliness, organizational issues, novelty, and speed), developed by Bates in 1988 and refined in 1995 to enable distance education to take advantage of technological developments when choosing specific media and technology applications for a course. Bates and Poole changed two aspects of the ACTIONS model: 1) they changed access to students in order to be relevant to any educational environment and level of flexibility and 2) they included ease of use with reliability (rather than interaction) because, if the technology is easy to use but unreliable, teachers will not use it to affect student learning.

The updated SECTIONS model has the following characteristics:

"It will work in a variety of learning contexts.

It allows decisions to be taken at both a strategic, institution wide level and at a tactical, instructional level.

It gives equal attention to educational and operational issues. 
It will identify critical differences between different media and technologies, thus enabling an appropriate mix to be chosen for any given context.

It is easily understood, pragmatic, and cost effective.

It will accommodate new developments in technology" (Bates \& Poole, 2003, p. 77).

As the SECTIONS model provides a practical framework with useful characteristics for teachers to select suitable software, it was used in the current study for the selection of software. In addition, Chapelle (1998, pp. 26-28) suggested seven criteria for developing multimedia CALL based on SLA theory as well as assessing language software:

"Making key linguistic characteristics salient

Offering modifications of linguistic input

Providing opportunities for 'comprehensible output'

Providing opportunities for learners to notice their errors

Providing opportunities for learners to correct their linguistic output

Supporting modified interaction between the learner and the computer

Acting as a participant in L2 tasks"

A second language (L2) is any language other than the native language or mother tongue (Mitchell \& Myles, 2004). Chapelle's evaluation criteria were also applied in the selection of software in the current study.

\subsection{Instructional Design}

Planning is an essential element of developing high-quality student-centered lessons using technology; indeed, it should include instructional design, media production, student support, and course evaluation and maintenance as well as the development and delivery of content (Bates et al., 2003). A well-prepared instructional design can help the teacher ensure that what is produced serves a necessary purpose, meets the needs of students, is attractive and well organized, is delivered in an appropriate mode, and is continually evaluated and improved (Morrison et al., 2004). Incorporating an effective developing technology-enhanced educational material into traditional courses is important for providing a complete instructional design plan to lead learners' performance successfully.

All instructional design models are constructed from a basic number of elements consisting of analysis, design, development, implementation, and evaluation phases (Yildiz, 2007). Morrison et al. (2004) defined instructional design as the systematic method of implementing the instructional design process through learning theories, information technology, systematic analysis, and management methods; its approach is based on considering instruction from the perspective of the learner-unlike traditional educational approaches, which stem from the perspective of the content. Morrison et al.'s comprehensive instructional design plan has nine elements:

A. "Identify instructional problems and specify goals for designing an instructional program.

B. Examine learner characteristics that will influence your instructional decisions.

C. Identify subject context, and analyze task components related to stated goals and purposes.

D. Specify the instructional objectives.

E. Sequence content within each instructional unit for logical learning.

F. Design instructional strategies so that each learner can master the objectives.

G. Plan the instructional message and develop the instruction.

H. Develop evaluation instruments to assess objectives.

I. Select resource to support instruction and learning activities" (Morrison et al., 2004, pp. 7-8).

Morrison et al.'s (2004) instructional design plan is graphically represented using an oval form with the nine elements incorporated (see Figure 1). Instructional planning can start from any of the elements according to which instructional design is appropriate for a potential project. It can follow the individual's preferred way as long as he or she considers it to be logical or suitable. The nine elements are not connected with lines or arrows, leaving the connection flexible even in cases that may not require addressing all nine elements. In addition, a flexible interdependence exists among the nine elements, which means decisions relating to one element affect other decisions due to the oval form. 


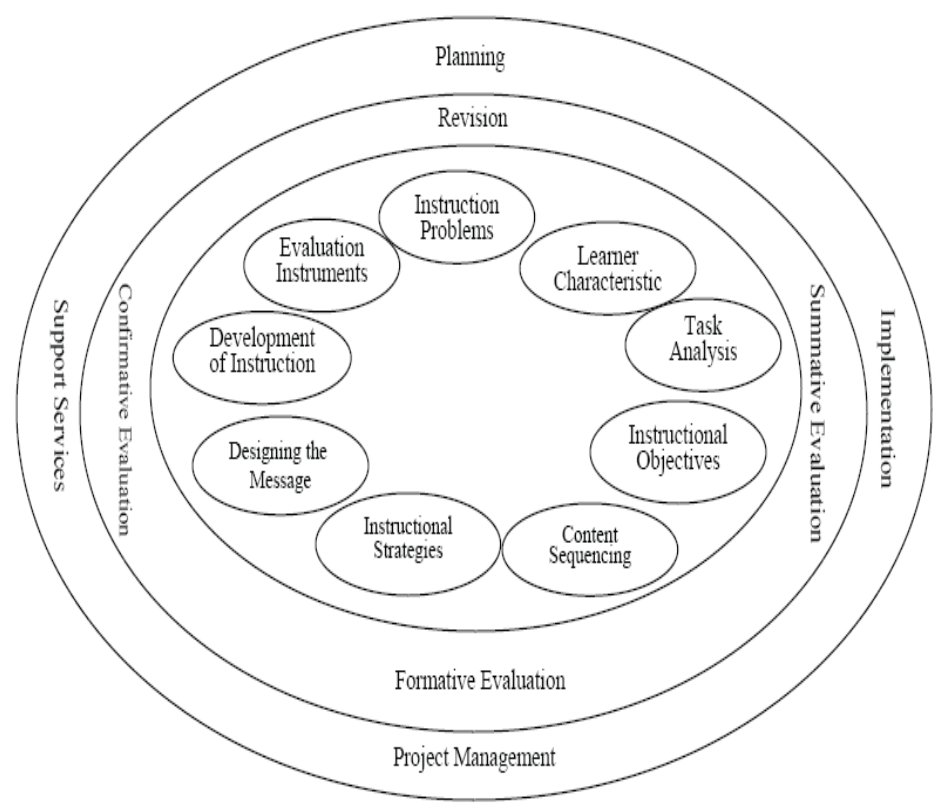

Figure 1. Components of the instructional design plan

Note. From Designing Effective Instruction (p.9), by Morrison, G, Ross, S., \& Kemp 2004, Hoboken, NJ: John Wiley \& Sons, Inc.

The instructional problems focus on identifying the need for instruction using a needs assessment plan and goal analysis. Morrison et al. (2004) defined needs as a gap between the present conditions and what is expected. Consequently, a needs assessment comprehensively analyzes needs to identify issues that participants face as well as ways that enable participants to approach the level of expected production. In other words, a needs assessment is a tool to help consultants determine clients' perceptions (Boiarsky, 2004). Meanwhile, learner characteristics describe learners' general characteristics, specific entry competencies, and learning styles. Morrison et al. (2004) mentioned the importance of determining - early in the initial design stages - which learners' characteristics were most useful in the current study as they impacted the way to design the instructional plan.

A contextual analysis for the instruction should be conducted in order to decide how to acquire the necessary information. According to Morrison et al. (2004), instructional objectives provide three functions: 1) instructors or designers can select the appropriate information and context of the instruction for the meanings of the objectives; 2) the objectives provide the base structure for evaluating learners, such as written tests, as designers and instructors design test items based on the objectives; and 3) learners can understand what they are going to learn from a lesson by knowing the objectives. The instructional objectives of the design instruct are written using the ABCD format, where $A$ is the audience who is going to learn and master the content from the tutorial, $B$ is the behavior (i.e., learners' ability to apply information from the instruction) students will master while completing the tutorial, $C$ is the conditions of performance including the resources or equipment students have access to (e.g., pictures and maps) and $D$ is the degree/level of achievement considered minimally acceptable for the performance standard (Morrison et al., 2004). The instructional strategy elements should subsequently be conducted in order to help learners achieve the objectives. Instructional strategies begin with determining the best fit in the context and performance type of each objective using the expanded content-performance matrix, which includes six categories: fact, concept, principle and rules, procedure, interpersonal, and attitude (Morrison et al., 2004).

Developing instructional strategy elements also involves implementing the instruction design plan in order to consider how to accurately convey information to learners in a manner they can comprehended by delivering a variety of instructional formats (e.g., class presentations, self-paced learning, and small-group interaction activities). Such formats can serve as evaluation instruments. According to Morrison et al. (2004), it is important to assess "To what degree did students accomplish the learning objectives prescribed for each unit of the course?" (p. 321). The best method is to examine the effectiveness of the instruction. 


\subsection{Oral Communication in Addressing Cultural Concepts with Technology}

Oral communication is an important step in learning a language and should be utilized in everyday interactions with the target language. Oral communication occurs through the individual's ability to decode input, process it, and simultaneously plan his or her output; this process is the same in both listening and speaking, as the individual needs to make immediate decisions about style, register, cultural referents, pronunciation, lexicon, and syntax (Abrams, 2003). Moreover, language reflects culture and is inherently tied to many of the linguistic concepts taught in second language classes (Peterson \& Coltrane, 2003). Thus, successful communication should include language use along with other culturally appropriate behaviors. Using computer technology, language learners can access more cultural concepts and develop a better sense of authentic situations using sound and pictures. In addition, shy or introverted language students may feel more comfortable speaking to an inanimate object (i.e., the computer) and therefore get more practice (Lacina, 2004).

In the Taiwanese language course context, students do not speak the target language in classes; as such, they are more hesitant generally to speak up in front of their peers when using the target language to practice oral language. In this regard, computer technology was able to help these less orally proficient students develop the self-confidence they need to use their oral skills.

Relationship of the Literature to the Study

Researchers and educators alike have proven the benefits of utilizing CALL environments to enrich the field of second language. Before integrating technology into courses, instructors must become fluent and critical users of technology in order to choose software applications that suit students' needs and provide relevant education. The comprehensive literature review had provided the rationale to select suitable software for use in the current study, building an instruction design to incorporate into traditional courses.

Applying and selecting software inappropriately could impede the achievement of learning outcomes. This study focused on integrating CALL technology into traditional courses in order to improve oral proficiency among Taiwanese speakers of English. The process and results could provide guidelines on how educational researchers can determine effective ways in which to integrate computer technology into classes as well as the challenges faced in selecting CALL software.

\section{Methodology}

\subsection{Research Design}

The current investigation used a quantitative approach to examine the improvement of oral performance among Taiwanese speakers of English by integrating CALL technology into traditional courses. A quantitative approach employs experiments and surveys to collect data via predetermined instruments while using post-positivist claims to develop knowledge such as the reduction of specific variables, hypotheses, and questions or the use of measurements and observations (Creswell, 2003). Gay et al. (2006) state that quantitative research aims to explain, predicts, and/or control phenomena of interest through the collection and analysis of numerical data. Furthermore, according to Gay et al. (2006) and Creswell (2003), in experimental research the researcher manipulates at least one independent variable, controls other relevant variables, and observes the effect on one or more dependent variable when one group receives a treatment while the other group does not. In this way, the researcher can isolate whether it is the treatment and not other factors that influences the outcome.

\subsection{Participants}

The sampling was purposefully chosen, which is called purposive sampling or judgment sampling (Gay et al., 2006). The study focused on integrating CALL technology into traditional courses in order to improve oral proficiency among Taiwanese speakers of English because Taiwanese students lack opportunities to speak English in an interactive environment. The researcher selected Taiwanese students who met certain criteria — namely; they were not majoring in English and were sophomores in traditional English classes in the target institution in Taiwan. This sampling approach allowed the researcher to better understand the improvement of oral performance among Taiwanese speakers of English by integrating CALL technology into traditional courses.

Participants comprised two sophomore English classes whose students were not majoring in English at a private university in Tainan, Taiwan. One class had 47 students and the other had 46 students. Fraenkel and Wallen (2000) and Gay et al. (2006) recommended that a minimum of 30 participants be in each group for treatment and non-treatment groups. Both classes were taught by the same instructor. The students were selected and randomly assigned to two groups: the experimental group and the control group. 


\subsection{Instrument Development}

The instrument was used for data collection: the PhonePass Spoken English Test (SET), which determined participants' improvement in oral proficiency. The PhonePass SET was developed by the Ordinate Corporation (http://www.ordinate.com); it is an individual test using telephones to measure speaking and listening skills as well as facility in spoken English, including the ease and immediacy in understanding and producing basic conversational English during a 10-minute interaction over the telephone. The test process includes six tasks: (a) read simple sentences, (b) repeat back sentences heard over the phone, (c) give short answers to questions, (d) build sentences out of words, (e) retell a story, and (f) answer two open-ended questions. The test is scored automatically by a computer-based system using automatic speech recognition. The overall scores are reported on a scale ranging from 20 to 80 and include scores on sentence mastery, vocabulary, fluency, and pronunciation. In addition, the description of overall test score and the candidate's capabilities are provided.

According to Buros Institute (2005), the Mental Measurement Yearbooks (MMYs) indicates that the reliability of SET is relatively high and the rate of reliability estimates are mostly above .90 . Correlations between machine and human scoring also tend to be above .90. In addition, MMYs presents correlations between the SET and various other tests, such as the Test of English for International Communication (TOEIC); such correlations are high-.70 or above-providing additional evidence for the concurrent validity of the test. According to the review in MMYs, the SET is a practical, reliable, and valid measure of proficiency in spoken, conversational English for nonnative speakers.

\subsection{Selecting CALL Software to Improve Oral Performance}

A major concern for many educators and software designers is the need to develop an effective process for selecting CALL software (Gosper et al., 2007). Both LCD and Krashen's SLA theories were utilized as guidelines for identifying the relevant CALL software. After identifying the software, Bates and Poole's (2003) SECTIONS model and Chapelle's (1998) evaluation criteria were used to select the most suitable program for achieving the goal. The benchmarks were followed in order to provide a genuinely helpful SLA environment that incorporates suitable software.

As previously discussed in the literature review, the six most popular CALL software programs that incorporated speech recognition technology were evaluated using Krashen's SLA theories and the LCD approach. According to the findings, successful communication should include language use along with other culturally appropriate behaviors; therefore, the contents of CALL software need to include the culturally appropriate use of the language and incorporated a variety of situational settings that were common in everyday environments.

Although the Traci Talk software program provided a vivid and interactive learning environment by engaging in role playing (i.e., a detective) and communicating with suspects in order to solve a mystery, its lack of coverage of cultural concepts meant that it was not considered. Meanwhile, the Rosetta Stone software used real-life images to connect meanings to new language and provided interactive and life-like conversations, making it very practical for learners' use in daily life. In addition, MyET (My English Tutor) incorporated local English learning magazines that addressed different topics each month on the MyET website, enabling learners to follow native speakers' reading of different articles to practice their oral performances. However, as both Rosetta Stone and MyET software provided only daily life language without incorporating any culture learning, they also did not fit the needs of the current study.

The remaining three software titles-Live Interactive English, Tell Me More, and Microsoft Encarta Interactive English Learning - covered different degrees of culturally appropriated use of the language and concepts. Thus, the next step was to use Bates and Poole's (2003) SECTIONS model and Chapelle's (1998) evaluation criteria to select the most suitable program for addressing the selecting of CALL software to improve oral performance.

Bates and Poole's (2003) SECTIONS model allowed for software selection from the teacher's perspective. The S refers to student: what is known about the students - or potential students - and the appropriateness of the technology for this particular group or range of students? The students were sophomore students learning English as a second language and majoring in non-English subjects. The students came from the same cultural background and traditional language learning system. According to Bates and Poole (2003), it could be dangerous to ask freshman and sophomore students to study a subject entirely through the use of technology as they have just graduated from high school and tend to be less independent learners; consequently, they will require more support and help when studying at the university and college level. Therefore, a more effective approach was taken in which the instructor explained to students how to use the technology and assisted students while using the technology. 
As the particular group of students included in the study did not speak the target language in class, they were hesitant generally to speak up in front of their peers when using the target language to practice oral language. In this regard, the CALL software used incorporated speech recognition technology to help these less orally proficient students acquired more practice to develop their self-confidence. All three software programs-Live Interactive English, Tell Me More, and Microsoft Encarta Interactive English Learning-included speech recognition technology to assist students in developing oral proficiencies.

The E in Bates and Poole's (2003) SECTIONS model refers to ease of use and reliability: how easy is it for both teachers and students to use and how reliable and well tested is the technology? The three software programs were evaluated using Krashen's SLA theories and the LCD approach as complex or poorly designed software can easily lead to confused and frustrated users, becoming problematic in typical studies of usability (Mendoza \& Novick, 2005). Following the guidelines, all three systems met the goal of LCD design and provided a comfortable second language environment. They had good user support in providing help on every screen and the ability to exit the system at any time without problems. The interfaces provided clear directions, and users could readily navigate throughout the system without difficulty. Thus, all three demonstrated ease of use and had good reliabilities.

The C in Bates and Poole's (2003) SECTIONS model stands for cost: What is the cost structure of each technology and what is the unit cost per learner? The Live Interactive English package included a monthly magazine and interactive CD-ROM as well as online formats for the price 8.80 US dollars per month per user. As the price was only for one month, ongoing learning required additional charges. The entire study period was eight weeks; therefore, every student in the experimental group required a two-month subscription, for a total of 17.6 US dollars per student for the entire treatment. Encarta Language Learning was available in a standard version that included the program CD and a microphone for 34.95 US dollars; the deluxe version included two audio CDs, a 240-page workbook, and a CD with full-screen videos for 54.95 US dollars per student for the entire treatment. Finally, the Tell Me More software package had two, five, or ten levels for 209, 309, and 499 US dollars, respectively. One package can be downloaded to a maximum of five computers, which meant 10 packages were required for the entire experimental group (47 students). An online format for an individual learner was also available, at a cost of 9.95 US dollars for a daily pass, 29.95 US dollars for a weekly pass, 75 US dollars for a monthly pass, 220 US dollars for a six-month pass, and 390 US dollars for a yearly pass. As the study period was eight weeks in length, prices for passes that lasted more than two months of study were not considered for the online format. The researcher provided the software and microphones to all participants so that they did not incur any costs.

Bates and Poole's (2003) SECTIONS model includes T, which represents teaching and learning: what kinds of learning are needed, what instructional approaches will best meet these needs, and what are the best technologies for supporting this teaching and learning? Any successful communication should include language use along with other culturally appropriate behaviors. Taiwanese learners often did not have opportunities to speak English; therefore, oral performance with the culturally appropriate use of language learning is needed. A system approach can be particularly valuable in ensuring the consistent quality of teaching for large classes (Bates et al., 2003). Therefore, Morrison et al.'s (2004) comprehensive instructional design plan was used to integrate the software into a traditional course. Due to the need was to improve learners' oral proficiency; speech recognition technology was incorporated as necessary support. All three software systems covered cultural learning and incorporated speech recognition technology to assist learning oral speaking.

The I in Bates and Poole's (2003) SECTIONS model refers to interactivity: what kind of interaction does this technology enable? The Live Interactive English was a package that included a monthly magazine and interactive CD-ROM. The magazine covered cultural topics, related conversations, a short story, live news reports, daily conversations, and hottest topics such as the newest movies and songs. The CD-ROM followed each topic to provide interactive 3-D animation, short movies with real people, MTV clips, and so on. Learners could control the native speaker's speed while reading the content and practice their oral performance by role playing and recording their own voices. In the culture learning, learners could learn from articles, 3-D animation, and short movies with real people by role playing, reading articles, or communicating with virtual characters to practice their oral skills.

Meanwhile, Encarta Interactive English Learning provided the ability to practice daily life language conversations related to topics such as traveling and asking directions by watching videos. Learners could control the speed of conversations and access grammar or cultural explanations. They could record their own voices after listening to a native speaker model and compare the differences. After finishing a unit, learners could practice role playing (called a virtual challenge) in a 3D virtual environment, in which learners moved around in a virtual space and interacted with certain characters. The software only provided cultural background explanations about the situations on a DVD, 
without incorporating oral practice.

The Tell Me More language software provided video scenes focusing on communication in everyday situations as well as interactive dialogues, pronunciation practice, and exercises for vocabulary and grammar structure acquisition. In the dialogue part, learners could choose one response from four possible responses presented on the screen; after saying the choice out loud, the dialogue developed to the learner's choice. However, this system provided limited interactions in the cultural workshop; the screens only provided explanations in symbolic concepts, things or people with images, and a subsequent screen asking a question from the prior screen. Learners did not have any oral practice based on what they learned in the cultural workshop.

Although Encarta Interactive English Learning and Tell Me More language software systems provided culture learning and interactive life-like conversations, the cultural learning sections did not include oral practices, only explanations. Therefore, neither software system was considered.

Bates and Poole's (2003) SECTIONS model include O for organizational issues: what are the organizational requirements and the barriers to be removed before this technology can be used successfully and what changes in organization need to be made? The computer labs and classrooms were available for students to use in the university, but not specifically for the language learning department. Consequently, the CALL software could not be installed on the computers. Due to university policy, the selected software must be available online or in a CD-ROM format. The Live Interactive English software could be accessed online or in a CD-ROM format.

Finally, the $\mathrm{N}$ in Bates and Poole's (2003) SECTIONS model stands for novelty-namely, how new is this technology? Live Interactive English software was designed in 2004 by the LiveABC Interactive Corporation, an innovator in designing language-learning tools. The basic goal for designing the software was to create a realistic and enjoyable environment through interactive 3-D animated dialogues, tutorials from renowned teachers, live situation short films, and popular music videos. According to Bates et al. (2003), it can be very dangerous to use leading-edge technology that has not been fully tested because the newest technology may be unreliable or difficult to use. However, given that Live Interaction English has been on the market for some years, it has adopted a policy of continually updating the design, incorporating new ideas. Thus, the system incorporates new technology while maintaining a base that was reliable and easy to use.

Bates and Poole's (2003) SECTIONS model also incorporates speed - namely, how quickly can courses be mounted with this technology and how quickly can materials be changed? Due to university policy, the software was accessed through the CD-ROM format, without directly installing it on the computer. The Live Interactive English system smoothly responded to input as indicated by the directions.

Based on Bates and Poole's (2003) SECTIONS model, Live Interactive English software was suitable for the current study. In addition, Chapelle's (1998) evaluation criteria were used to evaluate the software in order to select the most suitable program for achieving the goal. Chapelle (1998, pp. 26-28) suggested seven criteria for developing multimedia CALL based on SLA theory as well as assessing language software:

"Making key linguistic characteristics salient

Offering modifications of linguistic input

Providing opportunities for 'comprehensible output'

Providing opportunities for learners to notice their errors

Providing opportunities for learners to correct their linguistic output

Supporting modified interaction between the learner and the computer

Acting as a participant in L2 tasks"

The Live Interactive English software covered reading, writing, speaking, and listening areas while providing supporting vocabulary and grammar structure acquisition. The speaking part was the major component given the research goal of enhancing learners' oral proficiency.

Each article in the software system recorded a native speaker reading the text. As the native speaker read a sentence, the sentence was highlighted in different colors. Learners could control the speed of the native speaker (normal, slow, or repeat). All content could be read, and translations entries were available for every word. The system also included a reference word function; the screen showed new vocabulary with explanations and pronunciations. Learners could edit and add to their personal vocabulary lists. In addition, the system included a dictionary function for learners who want to see the vocabulary on the screen. 
In the role-playing function, learners could communicate with computers and record their own voices; when the learners' pronunciation was not correct, a pop-up window notified them, enabling learners to try again, omit, or hear the correct pronunciation again. In the interactive theatre, a virtual character communicated with learners; learners responded from offered answer lists. Two correct answers were included in the offered answers; the dialogue developed according to the learners' responses. Learners could ask for a cue from a virtual teacher. After the speech recognition technology analyzed the learners' speech, a notice showed whether the answer was correct or not. During the interaction with the computer, learners could choose to show captions or not to practice their listening. Learners could record their voices and compare them to a native speaker to discern their errors. Through the speech recognition technology, learners could correct their pronunciation with practice and listen to correct versions. Thus, the Live Interactive English software met the considerations from Bates and Poole's SECTIONS model and Chapelle's criteria to provide a comfortable learning environment; as such, it was the most suitable program for achieving the research goal.

\subsection{Instructional Design}

Morrison et al.'s (2004) comprehensive instructional design plan was used to integrate software into a traditional course. The instructional planning started from one of the elements (according to the instructional design) and followed a suitable method for working step-by-step to design the instruction. The instructional objectives were written using the $\mathrm{ABCD}$ format along with the instructional strategies associated with each objective.

\section{Instructional Objective One}

Sophomore English learners were able to choose the correct response in English in a culturally appropriate manner with at least a $10 \%$ improvement in accuracy when presented with a common and everyday situation.

Audience. Sophomore non-English major students were the audience.

Behavior. The targeted behavior was choosing the correct response in English in a culturally appropriate manner.

Conditions of performance. When presented with a common, everyday situation, learners spoke in an appropriate manner. These situations included cultural settings commonly encountered in everyday environments.

Degree/level of achievement. Learners completed the objective with at least a $10 \%$ improvement in accuracy from pretest to posttest. Although many mistakes were still made at this level, learners were able to communicate with a basic understanding.

Classification. The objective was classified as interpersonal skills. According to the generative strategies-context matrix (Morrison et al., 2004), the interpersonal skill-elaboration cell was the best match to the objective. The objective was at the evaluation level within the cognitive domain of Bloom's Taxonomy.

Initial presentation. Two common topics were presented-Fast Food Talking and Shopping English-and common expressions were listed along with a clear definition and examples. Learners learned the appropriate situations in which to say each expression by watching videos of real people recorded in real situations. Following each recording, learners practiced saying the sounds used in the expressions liked a native speaker. In order to help learners pronounce the expressions using the correct sounds, the software also provided speech recognition technology to assess pronunciation. In addition, learners could also record their voices to compare them to a native speaker's pronunciation.

General strategy and assessment of learning. The general strategy was the categorization of interpersonal skills. The learners were evaluated through fill-in-the-blank questions and role playing covering the appropriate elements. Learners had to determine the best and most appropriate answers and responded in the same situation by role playing; in addition, learners responded to fill-in-the-blank questions to demonstrate that they knew when to use the expressions appropriately.

Instructional Objective Two

After receiving explanations about how people in different countries celebrate Christmas, the sophomore English learners were able to judge the appropriate actions and expressions for specific situations in American culture with at least a $10 \%$ improvement in accuracy.

Audience. Sophomore non-English major students were the audience.

Behavior. The targeted behavior was judging appropriate or inappropriate actions in American culture.

Conditions of performance. Learners explained how people celebrate Christmas. 
Degree/level of achievement. Learners completed the objective with at least a $10 \%$ improvement in accuracy from pretest to posttest.

Classification. The objective was classified as a concept. According to generative strategies-context matrix (Morrison et al., 2004), the concept-organizational cell was the best match to the objective. The objective was at the evaluation level within the cognitive domain of Bloom's Taxonomy.

Initial Presentation. The content of understanding American etiquette was presented; learners listed different activities during Christmas in different countries. The content included clear explanations of each country and the appropriate ways to act and not act in these social situations.

General strategy and assessment of learning. The categorization of the concept was selected as the general strategy. The learners were assessed via fill-in-the-blank questions that covered the appropriate elements. Short stories were given; after learners read the stories, they were able to answer the questions given.

\section{Instructional Objective Three}

After showing a short movie involving real people speaking about American traditional festivals, the sophomore English learners were able to prepare for special activities included in a traditional American festival with at least a $10 \%$ improvement in accuracy.

Audience. Sophomore non-English major students were the audience.

Behavior. The targeted behavior was preparing for special activities in an American traditional festival.

Conditions of performance. The learners viewed short movies about traditional American festivals.

Degree/level of achievement: Learners completed the objective with at least a $10 \%$ improvement in accuracy from pretest to posttest.

Classification. The objective was classified as procedure. According to generative strategies-context matrix (Morrison et al., 2004), the procedure-integration cell was the best match to the objective. The objective was at the synthesis level within the cognitive domain of Bloom's Taxonomy.

Initial presentation. Two different short movies introduced traditional American festivals-namely, Thanksgiving and Christmas. Through simple, vivid, and engaging dialogues between real people and situations, learners could easily and clearly learn what American people usually do and eat during these festivals.

General strategy and assessment of learning. The categorization of the procedure was selected as the general strategy. The learners were measured using fill-in-the-blank questions and role playing that covered the appropriate elements.

\section{Instructional Objective Four}

After receiving vocabulary lists for different American festivals, sophomore English learners were able to choose the appropriate English words to use in different festival settings with at least a 10\% improvement in accuracy.

Audience. Sophomore non-English major students were the audience.

Behavior. The targeted behavior was choosing the appropriate words to say in English.

Conditions of performance. Learners received vocabulary lists for different American festivals.

Degree/level of achievement: Learners completed the objective with at least a $10 \%$ improvement in accuracy from pretest to posttest.

Classification. The objective was classified as a concept. According to generative strategies-context matrix (Morrison et al., 2004), the concept-organization cell was the best match to the objective. The objective was at the evaluation level within the cognitive domain of Bloom's Taxonomy.

Initial presentation. Before showing each movie about the traditional American festivals (i.e., Thanksgiving and Christmas), a vocabulary list relating to the festivals was presented. Learners were able to know the important words or vocabulary concepts according to these activities.

General strategy and assessment of learning. The categorization of the concept was selected as the general strategy. The learners were measured using a variety of matching and role playing questions that covered the appropriate elements. In the matching items, learners were able to choose the best verbal vocabulary that suited the picture. In the role playing, the learners chose the correct vocabulary according to a real situation.

Instructional Objective Five 
Using a short movie with real people about American traditional festivals, the sophomore English learners were able to write backgrounds or stories about different traditional festivals with at least a $10 \%$ improvement in accuracy.

Audience. Sophomore non-English major students were the audience.

Behavior. The targeted behavior was distinguishing between different traditional festivals.

Conditions of performance. Learners viewed a short movie.

Degree/level of achievement. Learners completed the objective with at least a $10 \%$ improvement in accuracy from pretest to posttest.

Classification. The objective was classified as a concept. According to generative strategies-context matrix (Morrison et al., 2004), the concept-integration cell was the best match to the objective. The objective was at the synthesis level within the cognitive domain of Bloom's Taxonomy.

Initial presentation. Two movies introduced the traditional American festivals - namely, Thanksgiving and Christmas. Through the simple, vivid, and engaging dialogues among real people in real situations, learners could easily and clearly learn about the festivals' origins and activities.

General strategy and assessment of learning. The categorization of the concept was selected as the general strategy. The learners were measured through role playing and story retelling that covered the appropriate elements. In the role playing, learners chose the most appropriate answers to complete the sentences about the festivals. In the short essays, learners used several pictures related to the activities to tell short stories about what they saw.

Throughout the five instructional objectives, students were encouraged to engage in the language and culture more directly in order to understand both more deeply. In the cognitive domain of Bloom's Taxonomy, students connected culture and language in order to analyze similarities to and differences with their own languages and cultures. They evaluated hidden or secondary meanings in cultural aspects as well, which enabled them to use what they learned effectively in a variety of situations and contexts. In addition, the verbs used in the behavioral aspect approach the higher order categories of analysis, synthesis, and evaluation in the cognitive domain.

\section{Contextual Analysis}

Orienting. In order to help learners have more opportunities to speak English fluently while enhancing their understanding of American culture, the goal of the teaching focused on enabling students to speak English correctly in a culturally appropriate manner, thereby improving their oral performance using CALL software. In addition—and related to this goal - learners sought to understand American culture more deeply.

As the students were learning English for various reasons, their perceived utility of the material varied. Ultimately they would be using the language to communicate; some when traveling, others in future business situations with colleagues. A few students were studying the language for personal development. However, considering the fact that the material combined both language skills and cultural knowledge, it was accessible and useful for everyone. Thus, the perceived usefulness of the material was high.

The software was user-friendly. Students were able to print out the instructions, and the software offered help in speaking English more fluently in a culturally appropriate manner. In addition, the software was portable, so students had access at all times, even without internet. As such, it was expected that students were quite motivated to use the software.

Instruction. The instruction was given to students during the English class. Learners who had registered for the sophomore English course in the experimental group received the material package, including software and one magazine. Since this software was aimed at an undergraduate language course, the computer lab was the instructional environment. The CALL software had been chosen accordingly.

Transfer. Since the software focused on the culturally appropriate use of the language, it incorporated a variety of situational settings that were common in everyday environments. The situations included environments such as the restaurant, the family, and the shopping mall. As such, the software provided applicable and authentic practice for real-world situations and it did so in such a way as to meet the needs of the students who did not have opportunities to speak English. Furthermore, important traditional American festivals were presented in this CALL software. Learners discovered the special details for preparing for the festivals and the in-depth background of the festivals.

Development of instruction. The self-paced learning method was used for delivering the instruction through a mixture of self-paced and group-paced instruction. The instructor provided some information on Chinese traditional cultures or festivals that were similar to the preselected topics in American cultures. For example, if the preselected 
topic was Christmas, the instructor discussed Chinese New Year celebrations with students and explained related vocabulary and phrases from the preselected topics. After the lecture, self-paced learning activities were provided to students using the CALL software. During the self-paced learning time, the instructor worked with individual students who had difficulty mastering the lectures or operating the CALL software.

Evaluation instruments. Participants in the experimental group used the CALL software to practice their oral proficiency in basic, common, daily-use language and special festivals. The best method for determining the degree to which students achieve the learning objectives is to examine the effectiveness of the course (Morrison et al., 2004). In order to measure the effectiveness of the CALL software, the objectives-based formative evaluation was used to measure how well the CALL software was achieving its objectives. The pretest-posttest design was used to compare the changes and differences between the experimental and control groups as well as the analysis of scores using SPSS (v14) software program. The average number of objectives accomplished per learner represented the percentage of learners satisfying each objective and the average percentage of objectives satisfied by all learners. Learners completed a pretest before the first day of the study to establish the baseline. After eight weeks, they took a posttest in order to evaluate the learning that had occurred. Therefore, the results determined the effectiveness of the software for learners.

\subsection{Determining Differences in SET Test Scores}

Once an appropriate second language learning environment was established-namely, one that utilized suitable software according to the benchmarks established and the SECTIONS model in the first phase as well as the well-prepared instructional plan according to Morrison et al.'s instructional design model — a nonequivalent control group design using quasi-experimental designs for experimental research was used so as not to involve the random assignment of participants to groups. In the nonequivalent control group design, two treatment groups were pretested, administered a treatment, and post tested (Gay et al., 2006). The identified software was used with one group of learners while the other group served as the control. Prior to initiating any learning activities, the SET was administered to all students to establish baseline scores. At the end of the teaching period, SET was administered again. The differences in test scores were analyzed to identify meaningful differences between students who received CALL technology instruction and those who received regular instruction only.

The treatment started in the fourth week of April and ran for eight weeks. Prior to the implementation, the researcher worked with the instructor in order to familiarize her with the CALL software and the instructional design. The participants took the SET test in an assigned room.

The English course met once a week for 100 minutes per session. The 100-minute block was divided into two sections of 50 minutes each. A 10-minute break occurred between the two sections. During the first section of every week, the instructor used the regular textbook and the preselected cultural or daily life topic as the teaching material to explain the related vocabulary and phrases, followed by a discussion with students of some of the related cultural questions in the experimental group. The second section used the Live Interactive English software in the computer lab. Before using the CALL software, the instructor leaded learners in a demonstration of how to use the software, providing any needed explanations. Next, students used self-paced learning with the CALL software to practice their oral skills for 40 minutes. If learners had any questions during the self-paced learning, the instructor assisted them. During the last 10 minutes, the instructor asked students questions from the content of the software in order to compare differences with their own cultures.

Finally, the control group was lectured using traditional instruction in both halves of the course in the classroom. They used the regular textbook and the Live Interactive English magazine with preselected topics and practiced exercises. The instructor explained the related grammar, vocabulary, and phrases and then lectured on the articles using a traditional teaching method.

Both groups covered the same material when the experimental group used the CALL software and the control group was lectured to from the magazine. In addition, both groups had the same amount of class time, the same teacher, and identical oral tests (pretest and posttest). In the eighth week, the SET test was administered to both experimental and control groups again. The differences in test scores between the pretest and posttest in the two groups were analyzed to identify meaningful differences.

\section{Results and Data Analysis}

According to Pearson Education (http://www.ordinate.com/), an overall score on the PhonePass SET achievement test ranging from 20 to 80 indicates the examinee's ability to understand spoken English and speak it intelligibly at a native-like conversational pace on everyday topics. However, if the examinee's voice was too soft to record or the 
context of the examinee's English could not be understood or was not related to the questions, the score would show "no score," which is the lowest possible score. The overall score is based on a weighted combination of four diagnostic subscores: sentence mastery, vocabulary, fluency, and pronunciation. Sentence mastery could affect examinees' ability to complete sentences, understand, recall, and/or produce English phrases and clauses. Performance depends on having meaningful sentence structures in accurate syntactic processing and appropriate usage of words, phrases, and clauses. Vocabulary could affect examinees' ability to understand common everyday words spoken in sentence context and producing needed words. Performance is based on familiarity with the form and meaning of everyday words and how examinees use them to connect speech. Next, fluency could affect examinees' rhythm, phrasing, and timing as evidenced in constructing, reading, and repeating sentences. Pronunciation could affect examinees' ability to produce consonants, vowels, and stress in a native-like manner in the sentence context. Performance depends on the ability to use everyday words from knowledge of the phonological structure.

A total of 46 students were in the control group. However, two students did not show up to take the pre-test, and one student did not show up for the posttest. Two students did not show up for either the pre- or posttest. The scores of students who took only one test - either the pre- or posttest - could not be compared; as such, these scores were deleted from the records. Consequently, 41 students total took both tests. In addition, eight students who took both tests did not register scores due to the fact that their voices were too soft or the context of their English could not be recognized during one or both tests. Thus, the scores of 33 students were used in the analysis.

In the experimental group, 47 students took both the pre- and posttests; 3 students did not show up for the posttest. Moreover, one student did not register any score on either test; eight students did not register a score on the pre-test and five students did not score on the posttest. As these students only scored on one test, their scores were also deleted from the analyzed data. Therefore, scores of 33 students were used.

The overall scores of the pre-test revealed that the mean of the control group was 28.21 and that of the experimental group was 29.30; the difference between the two groups was 1.09 (see Table 2), indicating that they were similar in SET ability. The ANOVA was conducted in order to determine whether a significant difference existed between the means of the two groups during the pre-test. The results $[\mathrm{F}(1,64)=.69, p=.41>.05]$ indicated that no significant difference existed between the two groups. Moreover, the two groups had very little or no difference in their pre-test levels, indicating that both groups had similar language ability before the treatment.

In the sentence mastery section of the pre-test, the mean was 29.91 in the control group and 31.61 in the experimental group - a difference of 1.70 between two groups. The corresponding ANOVA analysis $[\mathrm{F}(1,64)=.82$, $p=.37>.05]$ indicated no significant difference between the two groups. In the vocabulary section, the mean was 29.12 in the control group and 30.12 in the experimental group, for a difference of 1.00 . The ANOVA analysis [F (1, $64)=.31, p=.58>.05]$ indicated no significant difference between the two groups. Next, the fluency scores revealed a mean of 25.67 for the control group and 25.82 for the experimental group, for a difference of 0.15 . The ANOVA analysis $[\mathrm{F}(1,64)=.01, p=.91>.05]$ indicated no significant difference between the two groups. Finally, the mean of the pronunciation score was 30.06 in the control group and 31.33 in the experimental group - a difference of 1.27. The ANOVA analysis $[\mathrm{F}(1,64)=1.39, p=.24>.05]$ indicated no significant difference between the two groups. All four diagnostic subscores had no significant difference between the two groups during the pre-test, indicating that both groups had similar language ability. The fluency scores were the most similar between the two groups.

Following the eight-week treatment, both groups took the posttest. In the overall scores of the posttest, the mean of control group was 29.00 , while the experimental group's mean was 30.70 ; the difference between the two groups was 1.70. The ANOVA analysis $[\mathrm{F}(1,64)=1.83, p=.18>.05]$ indicated no significant difference between the two groups. Both groups showed improved during the posttest; although the groups' scores remained close, the difference between the two groups increased from 1.09 to 1.70 .

The four diagnostic subscores were also examined. In the sentence mastery posttest, the mean was 31.76 in the control group and 34.70 in the experimental group - a difference of 2.94. The ANOVA analysis $[\mathrm{F}(1,64)=2.29, p$ $=.14>.05]$ indicated no significant difference between the two groups. Although both groups improved their mean scores of sentence mastery between the pre- and posttests, the experimental group demonstrated the greatest improvement (a 3.1 change) while the control group improved only 1.86. The difference in improvement between the control and experimental groups grew from 1.70 in the pre-test to 2.94 in the posttest.

In the vocabulary section, the mean of the control group was 30.76 while that of the experimental group was 32.00 - a difference of 1.24. The ANOVA analysis $[\mathrm{F}(1,64)=.38, p=.54>.05]$ indicated no significant difference between the two groups. Both groups improved their mean scores for vocabulary; the difference between the two 
groups increased from 1.00 to 1.24 .

The fluency scores of posttest indicated a mean of 25.33 in the control group and 25.55 in the experimental group - a difference of 0.22 . The ANOVA analysis $[\mathrm{F}(1,64)=.03, p=.87>.05]$ indicated no significant difference between the two groups. Neither group performed as well in the vocabulary posttest as they did in the pre-test; the difference between the two groups indicated had a slight change.

Finally, the mean of the pronunciation score was 29.67 in the control group and 30.94 in the experimental group-a difference of 1.27. The ANOVA analysis $[\mathrm{F}(1,64)=1.81, p=.18>.05]$ indicated no significant difference between the two groups. Again, neither group performed as well in the pronunciation section of the posttest as in the pre-test; the difference between the two groups declined.

Table 2. Mean and Differences on Pretest and posttest for the Experimental and Control Groups

\begin{tabular}{lllllll}
\hline & \multicolumn{2}{l}{ Experimental } \\
& $\underline{\text { Pre }}$ & $\underline{\text { Post }}$ & $\underline{\text { Dif. }}$ & $\underline{\text { Pre }}$ & $\underline{\text { Post }}$ & $\underline{\underline{\text { Dif. }}}$ \\
\hline Overall & 29.30 & 30.70 & 1.40 & 28.21 & 29.00 & 0.79 \\
Sentence Mastery & 31.60 & 34.70 & 3.10 & 29.91 & 31.61 & 1.86 \\
Vocabulary & 30.12 & 32.00 & 1.88 & 29.12 & 30.76 & 1.64 \\
Fluency & 25.82 & 25.55 & -0.27 & 25.67 & 25.33 & -0.34 \\
Pronunciation & 31.33 & 30.93 & -0.40 & 30.06 & 29.67 & -0.39 \\
\hline
\end{tabular}

Both groups improved in their overall SET scores; the increases were close (control group: 0.79; experimental group: 1.40 ), and the difference in the change was only 0.61 . Although no significant difference occurred between the two groups on the posttest, the experimental group made greater improvement than the control group on the overall score. In particular, the experimental group showed greater improvement in the sentence mastery section (3.1) than the control group (1.86) after the treatment. The experimental group also made greater improvement in the vocabulary section (1.88) than the control group (1.64). However, neither group did as well on the fluency and pronunciation sections. The differences between the experimental group and the control group decreased on the posttest. In addition, the number of students that registered no score (due to speaking too softly or quitting during the test) decreased in both groups (see Figure 3); in the control group, the number dropped from seven to five, while in the experimental group it dropped from nine to six.

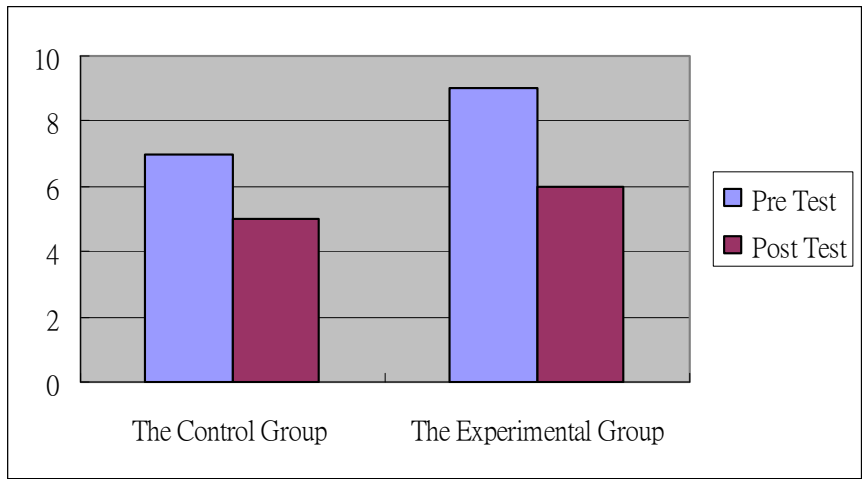

Figure 3. The number of students with no score

\section{Conclusions}

The study was designed to determine if CALL technology improves oral performance among Taiwanese speakers of English by enhancing traditional language instruction. Using CALL software can enrich students' experiences and assist their learning, yet teachers have to become proficient and critical users of technology, carefully choosing software programs from the overwhelming variety of software applications and despite the lack of standard measurements for computerized instruction in language learning. Many software applications do not support in-depth learning and are designed for profit rather than to benefit students (Hughes, 2005). Ineffective software can further result in poor learning (Susser, 2005). In addition, classroom learning often lacks the cultural aspect that makes 
language so multi-dimensional (Levy, 2007). Students may learn vast amounts of vocabulary without understanding the nuances of when to use a particular word or phrase.

In order to select the most suitable software for achieving the goal of improving Taiwanese oral performance, both learner-centered design and Krashen's second language acquisition theories were utilized as guidelines for identifying the six most popular computer-assisted language learning software programs that incorporated speech recognition technology. After identifying the software, Bates and Poole's (2003) SECTIONS(student, ease of use and reliability, cost, teaching and learning, interactivity, organizational issues, novelty, and speed) model was used to analyze and, in a step-by-step process, to select the most suitable program incorporating the culturally appropriate use of language as well as a variety of situational settings common in everyday environments. Finally, Chapelle's (1998) evaluation criteria were used to evaluate the selected software. Second language learning requires benchmarking to encourage a truly helpful learning environment while providing learners with a natural, safe, and supportive setting.

In order to integrate the selected CALL software into the traditional course, Morrison et al. (2004) a complete instructional design plan was designed and implemented to guide the instructional process. The instructional objectives were written using the ABCD format along with the instructional strategies associated with each objective. All five instructional objectives were listed, encouraging students to engage in the language and culture more directly and understand them more deeply. The contextual analysis included orientation, instruction, transfer, development of instruction, and evaluation instruments, which were planned in each subsequent step.

After completing the instructional design plan, a clear explanation to the instructor was needed to ensure that the instructor understood every step in order to get the best delivery during the treatment. The instructional design helped the instructor ensure that what was produced served the goal to meet students' needs.

Based on SET data, the pre-test indicated that the control (28.21) and experimental (29.30) groups had similar abilities, with only a 1.09 point difference in overall scores. The results of the ANOVA on the previous SET scores confirmed that no significant difference existed between the two groups prior to the treatment. Furthermore, the pre-test indicated that the control and experimental groups demonstrated similar abilities in the four diagnostic subscores. In the sentence mastery, the control group (29.20) and experimental group (31.60) had a 1.70 difference. In the vocabulary section, the control group (29.12) and experimental group (31.12) demonstrated a 1.00 difference. The difference in the fluency section between the two groups was 0.15 (control group, 25.67; experimental group, 25.82). The fluency had the smallest difference compared to the other three sections. Finally, in the pronunciation section, the control group (30.06) and experimental group (31.33) had a 1.27 point difference. The ANOVA analysis conducted on the four diagnostic subscores of the pre-test also indicated no significant difference between the two groups.

After eight weeks of treatment, both groups increased their overall scores on the posttest (control, 29.00; experimental, 30.70); the control group increased 0.79 and the experimental group increased 1.40, with a difference of 0.61. Although the results of the ANOVA analysis during the posttest indicated no significant difference in overall scores between the two groups, the experimental group made a slightly better improvement on the overall score than the control group, with the difference between the two groups increasing from 0.79 to 1.40 .

The ANOVA analysis conducted on the four diagnostic subscores of the posttest further indicated no significant difference between the two groups, although some changes compared to the pre-test were evident. Both groups increased on the sentence mastery score posttest (control, 31.76; experimental, 34.70); the control group increased 1.86 and the experimental group increased 3.10, with a difference 1.24. The experimental group made more improvement in sentence mastery than the control group, with the difference between the two groups increasing from 1.70 to 2.90 . In the vocabulary section, both groups also increased their scores on the posttest (control, 30.76; experimental, 32.00); the control group increased 1.64 and the experimental group increased 1.88, with a difference of 0.24 . The experimental group made slightly better progress on the vocabulary score than the control group, with the difference increasing from 1.00 to 1.24 .

However, both groups decreased their scores on the fluency and pronunciation sections of the posttest (control: fluency $=30.76$, pronunciation $=29.67$; experimental: fluency $=32.00$, pronunciation $=30.93$ ). The control group decreased 0.34 , and the experimental group decreased 0.27 , with a difference of 0.07 in the fluency section. The experimental group slightly regressed on the vocabulary score, more so than the control group, with the difference between the two groups decreasing from 0.15 to 0.22 . In the pronunciation section, the control group decreased 0.39 and the experimental group decreased 0.40 - a difference of 0.01 . 
The experimental group regressed more on the pronunciation score than the control group, with the difference between the two groups decreasing from 1.27 to 1.26. The reason for such a decrease might be that, when the experimental group used the software to practice their pronunciation, the sensitivity of the speech recognition technology could be adjusted from low to high. Most students adjusted the sensitivity to high or middle in order to get better correction. However, because the speech recognition technology was more sensitive, learners continually got a pop-up window notifying them that their pronunciation was not correct. The students became frustrated after practicing many times and still getting notification of being incorrect; thus, they ignored pop-up windows. As Lazar et al. (2006) defined, user frustration occurs when the computer acts in an unexpected way, annoying the user and preventing the user from reaching task goals. Therefore, learners did not get a better result on the posttest, which could affect their fluency because they became too sensitive about their pronunciation and needed more time to answer, which ultimately affected their rhythm, phrasing, and timing in constructing, reading, and repeating sentences.

In addition, the number of students who got no score declined in both groups. On the pre-test, seven students in the control group and nine in the experimental group did not score. After the treatment, the control group had only five students did not score and only six did not in the experiment group-decreases of two and three students, respectively. The experimental group also demonstrated some improvement regarding not feeling embarrassed to speak English in class.

\section{Implications}

The results make a meaningful contribution for integrating CALL software into traditional language courses with cultural concepts in Taiwan. They verified that CALL software is an effective learning tool for second language learning and serve as a testimony to the importance of the classroom teacher in the software-supported learning process. In addition, language teachers now have a model with an example of how to select suitable software from the overwhelming variety of CALL software applications and integrate it into their courses. The results contributed to the current knowledge base on designing CALL teaching and learning. Finally, the investigation contributed to helping language students who do not have many opportunities to utilize the target language in an authentic situation in a more meaningful and more in-depth learning environment.

The findings and insights gained from the experimental study were expected to have certain applicability to second language learning and educational practices. Comparing learners' own cultures with cultures of the target language provided the best way for understanding another culture. As learners acquire the ability to understand the context and culture of the other speaker, they also develop the ability to interact in the other culture in a meaningful manner (Rollin \& Harrap, 2005). Language educators need to address these needs as learners can learn the target culture in a real situation in their daily lives using CALL. Practical learning involving learners' real lives can help learners meet the situating social perspectives and interaction within cultural environments. Using a meaningful task, learners can engage more and effectively learn to manipulate the material they are learning (Quintana et al., 2001). Furthermore, the process of selecting software concepts can also be applied in different courses that need to use software to assist teaching with different theories to limit the overwhelming variety of software applications and choose the suitable software.

It is important that instructors be trained before the course starts. Educators must identify ways to incorporate the media effectively based not only on the needs of the students, but also within the confines of the educational system/environment (Wang, 2005). In order to be able to identify viable solutions, teachers must have ongoing technology training, especially as technology is constantly evolving (Susser, 2005). The educational system should focus on which skills instructors should master and what information should be incorporated into teacher education programs in order to prepare them to solve learners' problems - whether they are technology related or involve learners' mentality. For example, teachers should be equipped to deal with situations in which learners may not be familiar with the tools and, as a result, fail to use these tools at all.

Manipulating the number of trials, time-on-task, and time spent between trials was beyond the scope of the investigation. The technology itself served as a new experience for learners, many of whom were uncomfortable by the proximity of other students during the experiment. In addition, many students felt uneasy speaking loudly enough for the software to capture their words given the nearness of their peers. However, after several weeks, such hesitation and constraints seemed to have disappeared - or at the very least, lessened to a significant degree; consequently, students directed their focus to the authentic learning activities. Based on the observations, it seems likely that both mastery and learning would increase more quickly as learners became increasingly confident in their CALL use and had better computer access. 


\section{Recommendations}

The current investigation was primarily an experimental study designed to explore how to select and integrate CALL into traditional language courses to help students' oral performance. Through the insights and experiences gleaned, it is recommended to expand the second language research field, especially in regard to the traditional instruction system, and accumulate additional evidence related to CALL. Although the recommendations herein are made in regard to Taiwanese educational needs, studies with similar environments wanting to integrate software into their language courses can be conducted.

The English course in the current study was held once a week, which did not provide sufficient time to provide students with practice. In order to provide more opportunities for practice, students could borrow the software and return it the following week. However, only a few students did so. Students who have more time to practice (e.g., three times a week) can more effectively learn.

In addition, the computer lab was too small, requiring two students to sit next to each at one table while practicing. Although they had their own computers to use, they could still be affected by their classmates sitting next to them. Some shy students were afraid their classmates would hear them, so they tried to speak softly. In addition, two computers had some problems; one was shut down during the practice and the other was working too slowly. As such, two learners were interrupted and needed to change to other computers. It is recommend that computer labs be especially designed with better computer equipment for language learning use; students should have their own computers at one table without having to sit too close to each other. Lai (2006) pointed out that, despite the cost to the educational system for appropriate computer equipment and applicable software applications, these improvements make an immediate impact on language learning. Many schools do not have the budget available for state-of-the-art hardware that appropriate software requires. For example, some software requires the latest programming advances, but school computers may not have the necessary components to enable these advances to be used. In addition, some school computer systems may have less than ideal memory or speed for processing. Learners and teachers can become frustrated when waiting for slow computers to download large graphics or significant amounts of data using a dial-up connection when accessing the Internet (Lai, 2006). Therefore, proving a comfortable learning environment and equipment can help enhance learning while minimizing pressure and frustration.

The speech recognition technology analyses were highly sensitive. Learners could not achieve their requirement after practicing many times, so learners became frustrated and then tried to omit the software notification stemming from mistakes. Speech recognition technology needs to recognize learners' improvement as well as indicating mistakes. When learners are able to pronounce better, the pop-window can show some praise. If learners cannot pronounce items correctly to meet the requirement without improving, the pop-up window can show some encouragement while continuing the lesson, decreasing the degree of sensitivity automatically. Language educators need to consider individual learners' levels and pay attention to learners' reactions.

\section{References}

Abrams, Z. I. (2003). The effect of synchronous and asynchronous CMC on oral performance in German. Modern Language Journal, 87(2), 157-167. http://dx.doi.org/10.1111/1540-4781.00184

Barr, D., Leakey, J., \& Ranchoux, A. (2005). Told like it is! An evaluation of an integrated oral development pilot project. Language, Learning \& Technology, 9(3), 55-78.

Bates, A., \& Poole, G. (2003). Effective teaching with technology in higher education. San Francisco: Jossey-Bass.

Becker, K. (2006, June). How Much Choice is Too Much? Working group reports on Innovation and Technology in Computer Science. ACM, Bologna, Italy, 78-82.

Blease, D. (1986). Evaluating Educational software. Dover, NH: Croom Helm.

Boiarsky, C. (2004). The needs assessment: Using community consulting projects to teach business communication. Business Communication Quarterly, 67(1), 58-69. http://dx.doi.org/10.1177/1080569903262026

Buros Institute. (2005). Test review of the Test of English for International Communication. In Spies, R. A., \& Plake, B. S. (Eds.), The sixteenth mental measurements yearbook [Electronic version]. Retrieved January 25, 2009, from the Buros Institute's Test Reviews Online website: http://www.unl.edu/buros

Chapelle, C. A. (1998). Multimedia CALL Lessons to be learned from research on instructed SLA. Language Learning and Technology, 2(1), 22-34. 
Chen, J., Belkada, S., \& Okamoto, T. (2004). How a web-based course facilitates acquisition of English for academic purposes. Language Learning \& Technology, 8(2), 33-49.

Creswell, J. (2003). Research design: qualitative, quantitative, and mixed methods approaches ( $2^{\text {nd }}$ ed.). Thousand Oaks, California: Sage.

Delcloque, P. (2000). History of CALL. Retrieved November 20, 2008, from http://www.history-of-call.org/

Farmer, R., \& Hughes, B. (2005, July). CASE: A framework for evaluating learner-computer interaction in computer-assisted language learning. Proceedings of the 6th ACM SIGCHI New Zealand chapter's international conference on Computer-human interaction: making CHI natural. Auckland, New Zealand, 67-74.

Fraenkel, J. R., \& Wallen, N. E. (2000). How to design and evaluate research in education (4th ed.). New York: McGraw-Hill.

Gánem Gutiérrez, G. A. (2006). Sociocultural theory and its application to CALL: A study of the computer and its relevance as a meditational tool in the process of collaborative activity. ReCALL, 18(2), 230-251. http://dx.doi.org/10.1017/S0958344006000620

Gay, L. R., Mills, G. E., \& Airasian, P. (2006). Educational research: competencies for analysis and applications. Upper Saddle River, New Jersey: Pearson Prentice Hall.

Gosper, M., Woo, K., Muir, H., Dudley, C., \& Nakazawa, K. (2007). Selecting ICT based solutions for quality learning and sustainable practice. Australasian Journal of Educational Technology, 23(2), 227-247.

Hampel, R. (2006). Rethinking task design for the digital age: A framework for language teaching and learning in a synchronous online environment. ReCALL, 18(1), 105-121. http://dx.doi.org/10.1017/S0958344006000711

Hegelheimer, V., \& Tower, D. (2004). Using CALL in the classroom: Analyzing student interactions in an authentic classroom. Elsevier Ltd., 32, 185-205.

Heift, T., \& Toole, J. (2002). Student modeling in computer-assisted language learning. World Conference on Educational Multimedia, Hypermedia \& Telecommunications, Charlottesville, VA: AACE: 742-748.

Hincks, R. (2003). Speech technologies for pronunciation feedback and evaluation. ReCALL, 15(1), 3-20. http://dx.doi.org/10.1017/S0958344003000211

Hughes, J. (2005). The role of teacher knowledge and learning experiences in forming technology-integrated pedagogy. Journal of Technology and Teacher Education, 13(2), 277-302.

Iansiti, M. (1997). Technology Integration: Making Critical Choices in a Dynamic World. Boston, MA: Harvard Business School Press Boston.

Jepson, K. (2005). Conversations and negotiated interaction in text and voice chat rooms. Language Learning \& Technology, 9(3), 79-98.

Jiang, W., \& Ramsay, G. (2005). Rapport-building through CALL in teaching Chinese as a foreign language: An exploratory study. Language Learning \& Technology, 9(2), 47-63.

Karlstrom, P., Pargman, T. C., \& Ramberg, R. (2005). Designing for collaboration in intelligent computer assisted language learning. IEEE International Conference on Advanced Learning Technologies, 5, 321-322. http://dx.doi.org/10.1109/ICALT.2005.110

Knutsson, O., Pargman, T., \& Eklundh, K. (2003). Transforming grammar checking technology into a learning environment for second language writing. Association for Computational Linguistics, 2(6), 38-45.

Krashen, S. D. (1987). Principles and practice in second language acquisition. London: Prentice-Hall International.

Krashen, S. D. (1988). Second language acquistion and second language learning. London: Prentice-Hall International.

Krashen, S. D. (1994). Bilingual education and second language acquisition theory. In Bilingual Education Office (Ed.), Schooling and language-minority students: A theoretical framework ( $2^{\text {nd }}$ ed., pp. 47-75). Los Angeles: Evaluation Dissemination and Assessment Center, California State University.

Lacina, J. (2004). Promoting language acquisitions: Technology and English language learners. Childhood Education, 81(2), 113-116. http://dx.doi.org/10.1080/00094056.2005.10522253

Laghos, A., \& Zaphiris, P. (2005). Computer assisted/aided language learning. In C. Howard, J. V. Boettcher, L. Justice, K. Schenk, P. Rogers, \& G. A. Berg (Eds.), Encyclopedia of Distance Learning (Vol. 1, pp. 331-336). 
Hershey, PA: Idea Group Reference.

Lai, C. (2006). The advantages and disadvantages of computer technology in second language acquisition. National Journal for Publishing and Mentoring Doctoral Student Research, 3(1), 1-6.

Lazar, J., Jones, A., Hackly, M., \& Shneiderman, B. (2006). Severity and impact of computer frustration: A comparison of study and workplace users. Interacting with Computers, 18(2), 187-207. http://dx.doi.org/10.1016/j.intcom.2005.06.001

Lee, T. (2007). Improving English reading and listening by integrating a Web-based CALL system into classroom instruction. Journal of Instruction delivery systems, 21(3), 21-29.

Leonard, J., Davis, J., \& Sidler, J.(2005). Cultural relevance and computer-assisted instruction. Journal of Research on Technology in Education, 37(3), 263-285.

Levy, M. (2007). Culture, culture learning and new technologies: Towards a pedagogical framework. Language Learning \& Technology, 11(2), 104-127.

Liaw, M. (2006). E-learning and the Development of Intercultural Competence. Language Learning \& Technology, $10(3), 49-64$.

Lo, J., Wang, H., \& Yeh, S. (2004). Effects of confidence scores and remedial instruction on prepositions learning in adaptive hypermedia. Computers \& Education, 42(1), 45-63.

Luchini, K., Quintana, C., \& Soloway, E. (2003, April). Pocket PiCoMap: A case study in designing and assessing a handheld concept mapping tool for learners. Proceedings of the SIGCHI conference on Human factors in computing systems, Ft. Lauderdale, Florida, 321-328.

Luchini, K., Quintana, C., \& Soloway, E. (2004, April). Design guidelines for learner-centered handheld tools. Proceedings of the SIGCHI conference on Human factors in computing systems. ACM, Vienna, Austria, 135-142.

Mendoza, V., \& Novick, D. (2005, September). Usability over time. Proceedings of the $23^{\text {rd }}$ Annual International Conference on Design of Communication: Documenting \& Designing for Pervasive Information, Coventry, United Kingdom, 151-158.

Mitchell, R., \& Myles, F., (2004). Second language learning theories $\left(2^{\text {th }}\right.$ ed.). London: Hodder Arnold.

Morrison, G. R., Ross, S. M., \& Kemp, J .E. (2004). Designing effective instruction (4 ${ }^{\text {th }}$ ed.). Hoboken, NJ; John Wiley \& Sons.

Peregoy, S., \& Boyle, O. (2004). Reading, writing and learning in ESL: A resource book for K-12 teachers (4 ${ }^{\text {th }}$ ed.). Boston, MA: Allyn \& Bacon.

Peterson, E., \& Coltrane, B. (2003). Culture in second language teaching. Center for Applied Linguistics, Retrieved August 16, 2008, from http://www.cal.org/resources/Digest/digest_pdfs/0309peterson.pdf

Phillips, D., \& Soltis, J. (2003). Perspectives in learning $\left(4^{\text {th }}\right.$ ed.). New York: Teachers College Press.

Quintana, C., Krajcik, J., \& Soloway, E. (2001, August). Issues and methods for evaluating learner-centered scaffolding. Proceedings of IEEE International Conference on Advanced Learning Technologies. Madison, WI, 353-356. http://dx.doi.org/10.1109/ICALT.2001.943943

Quintana, C., Norris, C., Krajcik, J., \& Soloway, E. (2002, April). A case study to distill structural scaffolding guidelines for scaffolded software environments. Proceedings of the SIGCHI conference on Human Factors in Computing Systems: Changing our world, changing ourselves. ACM, Minneapolis, MN, 81-88.

Redfield, M., \& Campbell, P. D. (2005). Comparing CALL approaches: Self-access versus hybrid classes. The JALT CALL Journal, 1(3), 50-61.

Rollin, H., \& Harrap, A. (2005). Can E-Learning Foster Intercultural Competence? Brookes eJournal of Learning and Teaching, 3(1), Retrieved July 2, 2009, from http://cs3.brookes.ac.uk/publications/bejlt/volume1 issue3/practice/rollinharrap.pdf

Soloway, E., Guzdial, M., \& Hay, K. (1994). Learner-centered design: The challenge for HCI in the 21st century. Interactions, 1(2), 36-48.

Soloway, E., Jackson, S., Klein, J., Quintana, C., Reed, J., Spitulnik, J., et al. (1996, April). Learning theory in practice: Case studies of learner-centered design. Proceedings of the SIGCHI conference on Human factors in 
computing systems: common ground, ACM, Vancouver, Canada, 189-196.

Stepp-Greany, J. (2002). Student perceptions of language learning in a technological environment: Implications for the new millennium. Language, Learning \& Technology, 6(1), 165.

Susser, B. (2005). CALL and JFL teacher education in Japan: A course description. The JALT CALL Journal, 1(3), 3-16.

Wang, L. (2005). The advantages of using technology in second language education: Technology integration in foreign language teaching demonstrates the shift from a behavioral to a constructivist learning approach. T.H.E. Journal, 32(10), 38-42.

Ware, P. (2004). Confidence and competition online: ESL student perspectives on Web-based discussions in the classroom. Computers and Composition, 21(4), 451-468.

Yang, S., \& Chen, Y. (2007). Technology-enhanced language learning: A case study. Computers in Human Behavior, 23(1), 860-879. http://dx.doi.org/10.1016/j.chb.2006.02.015

Yildiz, I. (2007, June). "Ogretim Tasarimcisi” (instructional designer): an electronic performance support system for teachers in instruction design process. Proceedings of World Conference on Educational Multimedia, Vancouver, Canada, 1586-1595.

Zeiss, E. \& Isabelli-García, C. (2005). The role of asynchronous computer mediated communication on enhancing cultural awareness. Taylor \& Francis Group, 18(3), 151-169.

Zha, S., Kelly, P., Park, M., \& Fitzgerald, G. (2006). An investigation of communicative competence of ESL students using electronic discussion boards. Journal of Research on Computing in Education, 38(3), 349-367. 